\title{
Penatalaksanaan Anestesi Pasien Tetralogy of Fallot pada Operasi Mouth Preparation
}

\author{
Arsy Felicita Dausawati, Iwan Fuadi \\ Departemen Anestesiologi dan Terapi Intensif \\ Fakultas Kedokteran Universitas Padjadjaran Rumah Sakit Dr. Hasan Sadikin Bandung
}

\begin{abstract}
Abstrak
Tetralogy of Fallot (TOF) merupakan kelainan jantung bawaan yang terdiri atas ventricular septal defect, overriding aorta, stenosis pulmonal, dan hipertrofi ventrikel kanan. Tetralogy of Fallot termasuk kelainan jantung bawaan tipe sianotik. Seorang anak laki-laki 9 tahun datang untuk perawatan dan pencabutan gigi sebagai persiapan untuk operasi koreksi TOF di Rumah Sakit Dr. Hasan Sadikin Bandung pada Februari 2012. Anamnesis didapatkan riwayat kebiruan sejak bayi dan pada pemeriksaan fisis didapatkan anak yang tampak sianosis, $\mathrm{SpO}_{2}$ 70-75\%, murmur sistol, dan jari tabuh. Pada pemeriksaan ekokardiografi didapatkan kelainan TOF. Manajemen anestesi pada pasien ini dilakukan dengan menggunakan ketamin dan vekuronium untuk induksi serta pemeliharaan dengan $\mathrm{O}_{2}, \mathrm{~N}_{2} \mathrm{O}$, dan halotan. Serangan sianotik dapat terjadi preoperatif, intraoperatif, dan pascaoperatif yang diatasi dengan meningkatkan systemic vascular resistance (SVR) dibandingkan dengan pulmonary vascular resistance (PVR). Simpulan, prinsip pengelolaan perioperatif pembedahan nonkardiak pada pasien tetralogy of Fallot (TOF) adalah mencegah terjadi peningkatan shunt dari kanan ke kiri dengan menjaga agar tidak terjadi penurunan SVR, peningkatan PVR, dan menurunkan spasme infundibular
\end{abstract}

Kata kunci: Kelainan jantung kongenital sianotik, pulmonary vascular resistance (PVR), systemic vascular resistance (SVR), tetralogy of Fallot (TOF)

\section{Management of Anesthesia in Patients Tetralogy of Fallot which Undergo Mouth Preparation}

\begin{abstract}
Tetralogy of Fallot (TOF) is a congenital heart disease consisting of a ventricular septal defect, overriding aorta, pulmonary stenosis and right ventricular hypertrophy. Tetralogy of Fallot, including the type of cyanotic congenital heart defects. A boy of 9 years came for treatment and tooth extraction as preparation for the surgical correction of TOF at the Dr. Hasan Sadikin Hospital-Bandung whitin February 2012. Patients with a history of blue as a baby, and on physical examination found the child looking cyanosis, $\mathrm{SpO}_{2} 70-75 \%$, systolic murmur and finger clubbing. Abnormalities on echocardiography obtained TOF. Anesthetic management of these patients was performed using ketamine and vecuronium for induction and maintenance with $\mathrm{O}_{2}, \mathrm{~N}_{2} \mathrm{O}$ and halothane. Cyanotic attacks can occur preoperative, intraoperative and postoperative, who treated by increasing systemic vascular resistance (SVR) compared to pulmonary vascular resistance (PVR). In conclusions, perioperatif mangement principal for non cardiac surgery on tetralogy of fallot (TOF) is to prevent shunting from right to left by keep the SVR from decline, increase on PVR, and reduce infundibular spasme.
\end{abstract}

Key words: Cyanotic congenital heart defects, pulmonary vascular resistance (PVR), systemic vascular resistance (SVR), tetralogy of Fallot (TOF)

Korespondensi: Arsy Felisita Dausawati, dr., Departemen Anestesiologi dan Terapi Intensif, Fakultas Kedokteran Universitas Padjadjaran, Jl. Pasteur No. 38, Bandung, mobile 081374042559, email felicity2410@yahoo.co.id 


\section{Pendahuluan}

Tetralogy of Fallot (TOF) merupakan penyakit jantung bawaan sianotik yang paling banyak ditemukan, yaitu $\pm 10 \%$ dari penyakit jantung bawaan yang ada. ${ }^{1}$ TOF terdiri atas kombinasi beberapa kelainan jantung, yaitu ventricular septal defect (VSD), overriding aorta, stenosis pulmonal, serta hipertrofi ventrikel kanan. ${ }^{1-5}$ Etiologi TOF tidak diketahui pasti, pada 25\% pasien ditemukan dengan kelainan kromosom yang dihubungkan dengan defisiensi imun atau velocardiofacial syndrome dan juga submucous cleft palate. ${ }^{4,5}$

Manifestasi klinis TOF terutama disebabkan penurunan aliran darah pulmonal dan derajat sianosis TOF ditentukan oleh berat ringannya obstruksi aliran darah keluar ventrikel kanan (stenosis pulmonal). Obstruksi sirkulasi akan menyebabkan pirau dari ventrikel kanan ke ventrikel kiri. $^{1}$

\section{Laporan Kasus}

Seorang anak laki-laki berusia 9 tahun dengan diagnosis irreversible pulpitis dan periodontitis avikalis kronik disertai TOF dikonsulkan ke Departemen Anestesia Rumah Sakit Dr. Hasan Sadikin Bandung pada Februari 2012 untuk dilakukan mouth preparation dalam narkose umum.

Anamnesis didapatkan keterangan bahwa pasien mempunyai kelainan jantung bawaan sejak usia 5 bulan. Pasien mengalami kebiruan pada bibir dan ujung jari ketika menangis sejak berusia 2 minggu. Kebiruan pada kulit pasien ini kemudian menetap dan akan bertambah saat pasien beraktivitas atau apabila kurang beristirahat. Pasien sering kali menekuk kedua lututnya ke dada setelah berlari ataupun bila merasa kelelahan seperti bila menangis. Pasien tidak pernah dirawat ataupun menjalani terapi karena kelainan jantung. Pasien lahir spontan cukup bulan dengan berat badan lahir (BBL) $3,2 \mathrm{~kg}$. Ibu penderita tidak mengeluh kelainan pada saat hamil. Tidak ada riwayat kelainan jantung bawaan pada keluarga pasien. Saat ini pasien tidak mendapatkan terapi apapun.
Pada pemeriksaan fisis pasien didapatkan kesadaran kompos mentis, berat badan $19 \mathrm{~kg}$, tanda-tanda vital, yaitu tekanan darah 100/60 $\mathrm{mmHg}$, laju nadi $116 \mathrm{x} /$ menit, laju napas $22 \mathrm{x} /$ menit, $\mathrm{SpO}_{2} 70-75 \%$, suhu afebris, pada pemeriksaan kepala: konjungtiva tidak tampak anemis, sklera mata tidak tampak ikterik, bibir terlihat sianosis. Pemeriksaan Leher dalam batas normal. Pemeriksaan toraks didapatkan bentuk dan gerak dada simetris, pada jantung didapatkan bunyi jantung S1 dan S2 reguler, murmur sistol, pemeriksaan paru didapatkan bunyi suara napas bronkial vesikular menurun, ronki basah pada basal kedua paru, wheezing tidak ada. Pemeriksaan abdomen didapatkan bentuk abdomen datar, konsistensi lembut, dan bising usus normal. Pemeriksaan ekstremitas didapatkan akral hangat, ujung jari sianosis, terdapat clubbing finger. Hasil pemeriksaan laboratorium didapatkan kadar hemoglobin $25 \mathrm{~g} / \mathrm{dL}$, hematokrit 76\%, leukosit $8.300 / \mu \mathrm{L}$, trombosit $196.000 / \mu \mathrm{L}$, SGOT $33 \mathrm{U} / \mathrm{L}, \mathrm{SGPT}$ $11 \mathrm{U} / \mathrm{L}$, ureum $16 \mathrm{mg} / \mathrm{dL}$, kreatinin $0,40 \mathrm{mg} /$ dL, Na $142 \mathrm{mmol} / \mathrm{L}, \mathrm{K}$ 5,3 mmol/L, gula darah sewaktu $78 \mathrm{mg} / \mathrm{dL}$, PT 15,1 detik, INR 1,15, APTT 39,4 detik

Hasil pemeriksaan foto toraks didapatkan gambaran hipertrofi ventrikel kanan, segmen arteri pulmonal konkaf, corakan kedua paru berkurang, tidak ada gambaran tuberkulosis paru aktif. Hasil pemeriksaan ekokardiografi didapatkan gambaran berupa venticular septal defect (VSD) perimembran berukuran besar, stenosis pulmonal pada daerah infundibular, valvular moderat $44 \mathrm{mmHg}$, overriding aorta, hipertrofi ventrikel kanan, regurgitasi katup aorta derajat ringan, arkus aorta ke kiri, semua vena pulmonalis bermuara di atrium kiri.

Pasien dipuasakan selama 6 jam preoperasi kemudian dilakukan pemasangan infus untuk mencegah keadaan hipovolemia. Saat pasien dimasukkan ke dalam ruangan operasi dengan tanda vital: tekanan darah 131/94 mmHg, laju nadi $112 \mathrm{x} / \mathrm{m}$, laju napas $22 \mathrm{x} / \mathrm{m}, \mathrm{SpO}_{2} 72 \%$. Induksi dilakukan dengan memberi ketamin 40 mg dan vekuronium 2 mg intravena kemudian dilakukan intubasi dengan endotracheal tube no. 5.5 dengan kedalaman $16 \mathrm{~cm}$. Endotracheal tube dihubungkan dengan mesin anestesi dan 
pada saat operasi berlangsung pemeliharaan anestesi menggunakan $\mathrm{O}_{2}, \mathrm{~N}_{2} \mathrm{O}$, dan halotan. Hemodinamik selama masa operasi berkisar tekanan darah sistol 98-126 $\mathrm{mmHg}$, diastol 56-88 $\mathrm{mmHg}$, laju nadi $78-102 x /$ menit, laju napas $18-24 \mathrm{x} /$ menit dengan kontrol ventilasi positif secara manual, $\mathrm{SpO}_{2}: 81-83 \%$. Jumlah cairan yang diberikan $\pm 270 \mathrm{~mL}$ kristaloid.

Operasi telah berlangsung selama 2 (dua) jam dan diberikan obat analgetik pascaoperatif ketoprofen supositoria dosis $50 \mathrm{mg}$, kemudian pasien dipindahkan menuju ruang pemulihan. Pada saat di ruang pemulihan terjadi serangan sianosis dengan kondisi pasien tampak lebih sianosis dibandingkan dengan keadaan yang sebelumnya. Hasil pemeriksaan tanda vital anak diperoleh tekanan darah 100/52 mmHg, laju nadi $128 \mathrm{x} /$ menit, laju napas $28 \mathrm{x} /$ menit, dan nilai $\mathrm{SpO}_{2} 45 \%$. Tindakan yang dilakukan ketika serangan sianosis yaitu memposisikan pasien dengan knee-chest position, pemberian cairan, dan juga pemberian noradrenalin 0,04 mcg melalui jalur intravena. Keadaan pasien segera membaik dengan tanda vital tekanan darah $122 / 79 \mathrm{mmHg}$, laju nadi $105 \mathrm{x} /$ menit, laju napas $22 \mathrm{x} /$ menit, $\mathrm{SpO}_{2}$ 74\%. Pasien diobservasi di ruang pemulihan selama 2 (dua) jam dalam kondisi yang stabil dan kemudian dipindahkan ke ruang perawatan.

\section{Pembahasan}

Pada kasus di atas seorang anak datang untuk melakukan perawatan gigi sebagai persiapan untuk operasi koreksi tetralogy of Fallot (TOF). Keadaan ini dilakukan karena infeksi pada gigi dapat menjadi fokal infeksi terjadi komplikasi endokarditis terutama setelah operasi jantung.

Pemeriksaan pada penderita ini didapatkan tanda dan gejala yang sesuai dengan gambaran kelainan jantung bawaan yaitu tetralogy of Fallot (TOF). Pasien TOF akan terlihat sianotik sejak berusia 1 (satu) tahun dan akan semakin berat sejalan peningkatan aktivitas fisis anak. Serangan sianosis atau tet spells dapat terjadi baik secara spontan atau ketika anak sedang menangis, defekasi, agitasi, injuri, atau saat demam sehingga meningkatkan tonus simpatis dengan kontraktilitas jantung yang meningkat, serta akhirnya akan mengakibatkan spasme infundibular. Tet spells dapat dicetuskan oleh penurunan tahanan pembuluh darah sistemik (systemic vascular resistance/SVR) yang dapat terjadi pada saat induksi anestesi. Hal-hal lain yang memperberat kondisi sianosis ini adalah anemia, asidosis, infeksi, serta stres. Tet spells pada pasien yang sadar akan diikuti dengan hiperventilasi sebagai kompensasi mengatasi keadaan asidosis metabolik dan hipoksemia. ${ }^{1-5}$

Posisi menekuk lutut pada dada (squatting) sering kali dilakukan oleh anak dengan TOF. Hal ini diasumsikan bahwa SVR akan meningkat akibat arteri besar terlipat di daerah inguinal, peningkatan pada tekanan intraabdomen akan memperbesar aliran darah balik ke vena dan preload ventrikel jantung kanan. Peningkatan SVR akan menurunkan besar pirau dari kanan ke kiri sehingga aliran darah pulmonal dan oksigenasi arteri meningkat., ${ }^{2,4}$

Hasil anamnesis tidak didapat keterangan pasien mengonsumsi obat golongan antagonis $\beta$-adrenergik dan tidak ada riwayat dirawat di rumah sakit, sehingga pasien ini kemungkinan belum pernah mendapatkan komplikasi yang berat akibat TOF. Pada pemeriksaan auskultasi jantung terdengar suara murmur sistol pada daerah garis sternum kiri akibat aliran darah melewati katup pulmonal stenosis. Keadaan gagal jantung kongestif jarang terjadi akibat VSD berukuran besar, kondisi ini disebabkan tekanan intraventrikel terhadap beban jantung dalam keadaan seimbang. Hasil pemeriksaan laboratorium didapat konsentrasi hemoglobin tinggi yang merupakan kompensasi terhadap hipoksik kronik, sedangkan hasil pemeriksaan penunjang lain mendukung anomali jantung TOF, yaitu gambaran penurunan vaskularisasi paru dengan bentuk boot shaped pada jantung dan segmen arteri pulmonal yang cekung pada rontgen toraks. Hasil ekokardiografi diketahui derajat obstruksi pada ventrikel kanan, ukuran arteri pulmonal dan cabang-cabangnya, serta ukuran dan lokasi VSD..$^{1,2,4}$

Pasien dipuasakan 6 jam sebelum operasi, cairan intravena diberikan dengan tujuan agar tidak terjadi hipovolemia yang menyebabkan penurunan tahanan sistemik. Induksi anestesi menggunakan ketamin 40 mg intravena serta 
pelemas otot vekuronium dosis $2 \mathrm{mg}$.

Pemilihan ketamin intravena berdasarkan efek ketamin yang dapat meningkatkan denyut jantung, tekanan darah, cardiac output, serta menyebabkan peningkatan SVR yang dominan bila dibandingkan dengan tahanan pembuluh darah paru (pulmonary vascular resistance/ PVR). Ketamin juga mempunyai efek analgetik tanpa menimbulkan depresi napas.

Induksi juga dapat dilakukan menggunakan inhalasi memakai gas sevofluran atau halotan. Sevofluran tidak terlalu banyak memengaruhi hubungan SVR dengan PVR, karena sevofluran tidak hanya menurunkan SVR tetapi juga PVR. Penggunaan halotan memberikan SVR relatif lebih stabil dengan efek inotropik negatif yang lebih kuat sehingga mengurangi efek spasme infundibular, tetapi efek ini juga kurang disukai karena menimbulkan aritmia.

Golongan pelemas otot yang dipilih adalah golongan yang tidak menyebabkan pelepasan histamin yang akan menimbulkan vasodilatasi sistemik sehingga mengakibatkan penurunan SVR. Pemeliharaan anestesi dilakukan dengan menggunakan $\mathrm{O}_{2}, \mathrm{~N}_{2} \mathrm{O}$, dan halotan.

Saat operasi telah selesai, terjadi serangan sianosis di ruang pemulihan. Serangan sianosis ini dikenal dengan istilah hypercyanotic spell yang menandakan terjadi peningkatan shunt dari kanan ke kiri. Pasien segera diposisikan dengan kedua tungkai menekuk ke arah dada, lalu diberikan oksigen $100 \%$, cairan infus dan noradrenalin 0,04 mcg melalui intravena. Hal tersebut adalah usaha meningkatkan SVR agar lebih tinggi dibandingkan dengan PVR, karena serangan sianosis ini terjadi akibat PVR yang lebih tinggi daripada SVR.

\section{Simpulan}

Prinsip pengelolaan perioperatif pembedahan nonkardiak pada keadaan tetralogy of Fallot (TOF) ialah mencegah peningkatan shunt dari kanan ke kiri dengan menurunkan spasme infundibular serta menjaga agar tidak terjadi penurunan SVR dan peningkatan PVR, karena derajat dan juga arah shunting ditentukan oleh hubungan antara PVR dan SVR.

\section{Daftar Pustaka}

1. Schmitz ML, Ullah S. Anesthesia for right-sided obstructive lessions. Dalam: Andropoulos DB, Stayer SA, Russell IA, Mossad EB, penyunting. Anesthesia for congenital heart disease. Edisi ke-2. New York: Blackwell Publishing; 2005. hlm. 332-8.

2. Maranets I, Hines RL. Congenital heart disease. Dalam: Hines RL, Marschall KE, penyunting. Anesthesia and co-existing disease. Edisi ke-5. Philadelphia: Churchill Livingstone; 2008. hlm. 50-4.

3. Harrington JS, Shukla AC, Hickey PR. Anesthesia for surgical treatment of congenital heart disease. A problemoriented approach. Dalam: Eisenach JC, penyunting. Anesthesiology. New York: McGraw-Hill; 2008. hlm. 1197-200.

4. Lake CL, Booker PD. Tetralogy of Fallot. Dalam: Lake CL, Booker PD, penyunting. Pediatric cardiac anesthesia. Edisi ke4. Philadelphia: Lippincott Williams \& Wilkins; 2005. hlm. 345-57.

5. Hensley FA, Martin DE, Gravlee GP. Anesthetic management for patient with congenital heart disease. Practical approach to cardiac anesthesia. Edisi ke4. Philadelphia: Lippincott Williams \& Wilkins; 2008. hlm. 407-8.

6. Miller WC. Anesthesia for noncardiac surgery in children with congenital heart disease. Dalam: Coté CJ, Lerman J, Todres $D$, penyunting. A practice of anesthesia for infants and children. Philadelphia: Saunders-Elsevier; 2009. hlm. 483-4.

7. DiNardo JA, Zvara DA, Jacoby JJ. Congenital heart disease. Dalam: DiNardo JA, Zvara DA, penyunting. Anesthesia for cardiac surgery. Edisi ke-3. Massachussetts: Blackwell Publishing; 2008. hlm. 206-12. 